\title{
Early detection of laryngeal cleft in infants by novel technique of flexible endoscopy with sustained pharyngeal inflation
}

\author{
Wen-Jue Soong ${ }^{1}$, Chia-Feng Yang ${ }^{2}$, Pei-Chen Tsao ${ }^{3}$, Yi-Hung Sung ${ }^{4}$, and Yen-Hui Soong ${ }^{5}$ \\ ${ }^{1}$ Children's Hospital, China Medical University \\ ${ }^{2}$ Taipei veterans general hospital \\ ${ }^{3}$ Veteran general hospital, Taipei, Taiwan (ROC) \\ ${ }^{4}$ Mackay Memorial Hospital \\ ${ }^{5}$ Michigan State University College of Human Medicine
}

November 3, 2021

\begin{abstract}
Objective: Report a novel technique of flexible endoscopy (FE) with noninvasive ventilation (NIV) and sustained pharyngeal inflation (FE-NIV-SPI) in assessing aeroesophageal tracts (AET) to facilitate early detect laryngeal clefts (LC). Methods: Medical charts and FE videos of the children who were diagnosed as LC in a tertiary care hospital between 2000 and 2020 were retrospectively reviewed and analyzed. FE-NIV-SPI technique was applied for all the reviewed children. Results: Of all the FE videos reviewed, twelve infants with laryngeal clefts were collected. This equates to a prevalence of $0.28 \%$ in all the children underwent FE at our institution. Their mean age was $5.0 \pm 4.9$ month-old and the mean body weight was $4.7 \pm 2.3$ $\mathrm{kg}$. Nine $(75 \%)$ infants were referred in without LC diagnosis, which was missed by 11 prior bronchoscopy and 5 computer tomography exams. With FE-NIV-SPI, the pharyngolaryngeal space could be pneumatically expanded and allowed detailed assessment. All LC types and coexisted AET lesions were visualized at the first FE-NIV-SPI examination with a mean time of $4.2 \pm 0.9$ minutes. They were eight type I, two type II and one type III. Ten $(83.3 \%)$ infants coexisted airway malacia. Conclusion: Routinely using the FE-NIV-SPI technique can help detect the LC defect and associated AET lesions at the first assessment.
\end{abstract}

Title pages

Early detection of laryngeal cleft in infants by novel technique of flexible endoscopy with sustained pharyngeal inflation

Wen-Jue Soong, ${ }^{1,2,3}$ Pei-Chen Tsao, ${ }^{2,3}$ Chia-Feng Yang, ${ }^{2,3}$ Yi-Hung Sung, ${ }^{4}$ Yen-Hui Soong ${ }^{5}$

${ }^{1}$ Division of Pediatric Pulmonology, Children's Hospital, China Medical University, Taichung, Taiwan;

${ }^{2}$ Department of Pediatrics, Taipei Veterans General Hospital, Taipei, Taiwan;

${ }^{3}$ Department of Pediatrics, School of Medicine, National Yang Ming Chiao Tung University; Taipei, Taiwan;

${ }_{4}^{4}$ Pulmonary and critical care, Paloma Medical Group; Los Angles, California, USA;

${ }^{5}$ Department of Medical Education, MacKay Memorial Hospital, Taipei, Taiwan

Key words : bronchoscopy, flexible endoscopy, flexible laryngoscopy, laryngeal cleft, noninvasive ventilation, sustained pharyngeal inflation, Soong's ventilation

Abbreviated title: Flexible endoscopy with sustained pharyngeal inflation detect laryngeal cleft 
Corresponding (reprint request) author:

\section{Wen-Jue Soong, MD}

Division of Pediatric Pulmonology, China Medical University Children's Hospital, Taichung, Taiwan.

No. 2, Yuh-Der Road, Taichung 40447, Taiwan.

Phone: +886-4-22052121 ext. 4648;

Fax.: +886-4-22032798;

Cell phone: $+886-921067989$;

E-mail: wjsoong3@gmail.com

\section{Financial disclosure:}

- This study was granting supported and IRB proved by Taipei-Veterans General Hospital (VGHIRB: No. 2018-11-002BC).

- There is no support from any commercial manufacture or company about this study.

- The first author, Wen-Jue Soong, wrote the first draft of the manuscript.

- Report to Pediatric Pulmonology : on behalf of all authors, the corresponding author states that there is no conflict of interest with any person or company.

Authors list

\begin{tabular}{|c|c|c|c|c|}
\hline Name & $\begin{array}{l}\text { Highest } \\
\text { academic } \\
\text { degree }\end{array}$ & E-mail & $\begin{array}{l}\text { Contribution } \\
\text { statement }\end{array}$ & Affiliation \\
\hline $\begin{array}{l}\text { Wen-Jue } \\
\text { Soong }{ }^{1,2,3}\end{array}$ & MD. & $\begin{array}{l}\text { wjsoong3@gmail.com } \\
\text { Orcid id: 0000- } \\
\text { 0002-8397-4956 }\end{array}$ & $\begin{array}{l}\text { Conceptualization, } \\
\text { Methodology, } \\
\text { Investigation, } \\
\text { Resources, } \\
\text { Writing-original } \\
\text { draft, } \\
\text { Supervision. . }\end{array}$ & $\begin{array}{l}\text { Division of Pediatric } \\
\text { Pulmonology } \\
\text { Children's Hospital, } \\
\text { China Medical } \\
\text { University } \\
\text { Taichung, Taiwan. } \\
\text { Department of } \\
\text { Pediatrics, Taipei } \\
\text { Veterans General } \\
\text { Hospital, Taipei; } \\
\text { School of Medicine, } \\
\text { National Yang-Ming } \\
\text { University; Taipei, } \\
\text { Taiwan Department } \\
\text { of Medical } \\
\text { Education, Taipei } \\
\text { Veterans General } \\
\text { Hospital, Taipei, } \\
\text { Taiwan Paloma } \\
\text { Medical Group, Los } \\
\text { Angles, California, } \\
\text { USA; }\end{array}$ \\
\hline Pei-Chen Tsao 2,3 & $\mathrm{MD}, \mathrm{PhD}$ & $\begin{array}{l}\text { tsao3840@gmail.com } \\
\text { Orcid id: } \\
\text { 0000-0003-1613-653 }\end{array}$ & $\begin{array}{l}\text { Investigation, } \\
\text { Project } \\
\text { administration, }\end{array}$ & \\
\hline
\end{tabular}




\begin{tabular}{|c|c|c|c|c|}
\hline Name & $\begin{array}{l}\text { Highest } \\
\text { academic } \\
\text { degree }\end{array}$ & E-mail & $\begin{array}{l}\text { Contribution } \\
\text { statement }\end{array}$ & Affiliation \\
\hline Chia-Feng Yang ${ }^{2,3}$ & $\mathrm{MD}, \mathrm{PhD}$ & $\begin{array}{l}\text { pum_- } \\
\text { chia@yahoo.com.tw } \\
\text { Orcid id: 0000- } \\
\text { 0001-5739-5216 }\end{array}$ & $\begin{array}{l}\text { Software, Formal } \\
\text { analysis, }\end{array}$ & \\
\hline Yi-Hung Sung ${ }^{4}$ & $\mathrm{MD}$ & $\begin{array}{l}\text { yheddysung@gmail.con } \\
\text { Orcid id: 0000- } \\
\text { 0002-8423-5223 }\end{array}$ & $\begin{array}{l}n \text { Writing-review \& } \\
\text { editing }\end{array}$ & \\
\hline Yen-Hui Soong ${ }^{5}$ & $\mathrm{MD}$ & $\begin{array}{l}\text { msoongy@gmail.com } \\
\text { Orcid id: 0000- } \\
\text { 0001-8640-8784 }\end{array}$ & $\begin{array}{l}\text { Validation, } \\
\text { Writing-review \& } \\
\text { editing }\end{array}$ & \\
\hline
\end{tabular}

\section{Introduction}

Laryngeal cleft (LC), a fissure defect between laryngotrachea and upper esophagus, is a rare congenital anomaly occurring in less than $0.1 \%$ of the general population. ${ }^{1-3} \mathrm{LC}$ is important to be early recognized to prevent unnecessary diagnostic work-up, medication and associated morbidities. The main presenting symptoms of stridor, chronic cough and recurrent aspiration are non-specific. Direct visual confirming its presence and identifying type are clinically challenging. Rigid endoscopy (RE) is capably separating and inspecting inter-arytenoids and hypopharyngeal region, therefore, being recommended as confirmatory diagnosis of LC. ${ }^{3-7}$ However, due to the need for general anesthesia, lack of RE expertise in many centers, the application of RE can be challenging in common practices for diagnosing LC.

Flexible endoscopy (FE) allows direct inspection of the dynamic structures of pharyngolaryngeal space (PLS) and aeroesophageal tracts (AET), therefore is the preferred first-line visual examination. ${ }^{8}{ }^{9}$ However, defects in the posterior larynx may not be readily noticeable due to the inherent collapse hypopharynx, which usually displays a normal appearance. Even with apparent symptoms and a high index of suspicion, LC could still be overlooked by experienced operator using traditional FE technique. ${ }^{3,10,11}$ Trachsel's group published a report of FE assisted with using continuous positive airway pressure via an endoscopy face mask for the diagnosis of LC. ${ }^{12}$ We here like to share our experiences by applying a more simple technique of positive airway pressure (PPV) to evaluate LC.

"Pharyngeal oxygen with optional nose-closure and abdomen-compression $\left(\mathrm{PhO}_{2}\right.$-NC-AC)" is a novel technique of noninvasive ventilation (NIV). ${ }^{13-15}$ Clinically, it is a safe and convenient method of producing PPV without using any ventilation or airway devices of Ambu-bag, face mask, nasal prong, laryngeal mask airway, endotracheal tube or ventilator. FE with this NIV (FE-NIV) can ensure adequate oxygenation during many interventional procedures of AET in pediatrics, even in severe asphyxiated status. ${ }^{16-18}$ In this NIV, maneuvers of prolonged nose-closure, 1 to 5 second, can create sustained pharyngeal inflation (SPI) with enough, dynamic and controllable PPV to expand the PLS and allows precise FE assessment. ${ }^{19}$ Over the last two decades, we have routinely using this FE-NIV and SPI (FE-NIV-SPI) technique and have successfully detected many LC lesions at their first FE inspection of larynx.

We like to share our experiences using this novel FE-NIV-SPI technique alone to screen for LC lesions and report characteristics of our patients.

\section{Methods}

A retrospective study was conducted in Taipei Veterans General Hospital, a tertiary care medical center. Many pediatric patients in Taiwan and surrounding countries with complex airway diseases needing bronchoscopy interventions evaluation. FE number was 400 to 500 per year in the last two decades. Medical 
charts and associated FE videos of pediatric patients who were diagnosed of LC between January 2000 and December 2020 were reviewed and enrolled in this study. Their demographic and clinical data were collected and analyzed. This study was approved by the Medico-Ethical Committee of hospital (VGHIRB: No. 2018-11-002BC).

\section{FE-NIV preparation}

FE patients followed a standard preparation. Procedural sedation of intravenous midazolam 0.1-0.2mg/kg, ketamine $1-2 \mathrm{mg} / \mathrm{kg}$ and atropine $0.01 \mathrm{mg} / \mathrm{kg}$ was given to keep patient motionless yet still maintain spontaneous breathing. Topical anesthesia of $2 \%$ lidocaine solution, $1.0 \mathrm{ml} / \mathrm{kg}$, was applied via syringe catheter into patient's nostrils and trachea. A continuous oxygen flow $(1.0 \mathrm{~L} / \mathrm{Kg} / \mathrm{min}$, maximal $10.0 \mathrm{~L} / \mathrm{min})$ delivered through a small nasopharyngeal catheter as the "pharyngeal oxygen, $\mathrm{PhO}_{2}$ ". $\mathrm{PhO}_{2}$ - $\mathrm{NC}-\mathrm{AC}$ technique was routinely used to ensure adequate oxygenation and ventilation during the entirety of FE procedure. Vital signs including heart rate, respiration, oxygen saturation and blood pressure were continuously monitored.

FE performed with a short working-length $(30 \mathrm{~cm})$ flexible endoscope, outer diameter $2.6 \mathrm{~mm}$ or $3.2 \mathrm{~mm}$ (Olympus, ENF-V2 or ENF-V3), without inner cannel. Flexible bronchoscope was introduced into the nasal tract and advanced into the supraglottic region. With chin lift maneuver, the entire larynx including the epiglottis, arytenoids, vocal cords and hypopharynx could be visualized. (Figure 1a) During nose-open phase, the posterior laryngeal commission and hypopharyngeal wall may appose each other and resulted a collapsed esophageal inlet.

\section{FE-NIV-SPI assess AET}

During FE-NIV assessment, SPI was optionally done by right hand of operator (Figure 1b) with index finger hooked patient's chin to pull and close patient's mouth, thumb and mid-finger pinch-closed patient's nose. SPI of 1 to 5 seconds, as required, was applied to gradually inflate and expand spaces of supraglottis and hypopharynx for clear FE inspection. ${ }^{19}$ In case of LC, a deep fissure over the posterior larynx could be observed. The size of the defect and its relationship with surrounding structures were measured by manipulating scope tip or using forceps. The scope was then advanced into the tracheobronchial and the esophageal lumens for further evaluation. Types of LC were based on the Benjamin and Inglis classification. ${ }^{20}$ SPI maneuver with duration of 3 to 5 seconds could be repeated as necessary. Between each SPI, patient was allowed spontaneous breaths or supported with NIV for at least 10 seconds. The time of making a complete diagnosis, from insertion of endoscope to final confirmation of the LC type, was captured from the video recording.

After completion of FE procedure, abdomen compressions and gastric suctions were routinely performed to eliminate air distention. A post-procedural chest radiography was routinely checked for possible complications of air leak or damages.

\section{RESULTS}

Over the 20-year period, a total of 8,125 FE procedures of AET were performed in 4,227 patients. Among them, 12 infants ( 7 male, 58.3\%) had a diagnosis of LC, with an incidence of $0.28 \%$ in our FE patients. Of these infants, 8 was type I, 3 was type II, and 1 was type III (Table 1). These LC diagnosis were all made in their first FE-SPI examination. The type III LC was further confirmed with RE. At the time of FE diagnosis, their mean age was $5.0 \pm 4.9$ (ranged from 6 hours to 18 months) months old, the mean body weight was $4.7 \pm 2.3$ (ranged from 2.7 to 10.6 ) $\mathrm{kg}$.

Nine $(10 / 12,83.3 \%)$ infants were referred from other hospitals, included 7 infants from 6 tertiary children's hospitals and 2 infants from neighboring countries, for management of their refractory respiratory problems. Among them, before admitted to our hospital, 7 infant's airway were already examined with $11 \mathrm{FE}$ and 5 computed tomography studies, no LC was found. Nine infants had failure to thrive. Four infants had tracheal intubation and 3 had prolonged mechanical ventilation support due to pneumonia, respectively. All 12 FE-SPI procedures were performed within three hours of admission. 
Under FE-SPI inspection, the whole PLS could be gradually lifted and clearly visualized. In particular supraglottis, bilateral arytenoids with redundant tissue and cleft itself could be pneumatically separated and precisely identify its type, included depths of the cleft. All the LC lesions of these 12 infants were successfully recognized at their first FE-SPI examination of the larynx before checking the tracheal or esophageal lumens. The time for a complete diagnosis of LC ranged from 3.0 to 5.5 minutes, with a mean of $4.2 \pm 0.9$ minutes. Ten $(90.9 \%)$ infants coexisted with airway abnormalities including 9 infants $(9 / 12,75.0 \%)$ with laryngomalacia and 3 infants $(3 / 12,25.0 \%)$ with tracheal or bronchial malacia. Four infants $(4 / 12,25.0 \%)$ had coexisting gastroesophageal reflux.

All infants tolerated the FE-SPI procedure. No associated complications such as oxygen desaturation $(<$ $90 \%$ ), bradycardia (heart beat $<100 / \mathrm{min}$ ), ear drum perforation, subcutaneous air leak, pneumothorax or AET bleeding were noted.

\section{DISCUSSION}

FE-NIV-SPI is a safe and simple technique that can be routinely applied under common procedural setting to detect LC in infants. The usage of nasopharyngeal catheter to deliver continuous oxygen flow and application of nose-closure maneuver to generate airway pressure to expand PLS and AET lumens, allowing detailed visualization of the LC.

Hypoxia and hypoventilation are frequent complications of pediatric FE interventions, therefore the usage of supplemental oxygen and PPV are highly recommended. ${ }^{21-23}$ Without pneumatic stenting of SPI, as traditional method of $\mathrm{FE}$, hypopharynx, posterior larynx and upper esophagus remain collapsed and the LC may otherwise stay undetected. Over the past two decades, we have incorporated FE-NIV-SPI technique as the default method to maintain oxygenation and ventilation in our endoscopic practice. This allows us to perform many bronchoscopic interventions that otherwise cannot be safely performed in infants with severe asphyxia condition. ${ }^{13-19}$ If FE-NIV-SPI is routinely applied in all FE, this review suggest that it may detect more LC at the first laryngeal examination. Although the deeper involved lesions, such as type IV, may still need a RE to confirm, the most commonly types of I, II and III LC defects can be diagnosed reliable with FE-NIV-SPI. That may allow waiving more invasive and complicated procedures of RE, general anesthesia and radiologic examinations.

For LC, an early diagnosis is crucial for subsequent management to prevent morbidity or mortality. Traditionally, being widely available and easily handled, FE plays an essential role in exploring lesions that cause airway and respiratory problems in pediatric patients. ${ }^{24-26}$ However, FE has not been considered a commendable tool to evaluate the posterior commissure of the larynx where lesion as LC may fail to recognize. ${ }^{27} \mathrm{RE}$ is more capable and remains the gold standard for confirmation of LC. ${ }^{3-7}$ However, there may have technical difficulties and risky, especially in small infants who already have respiratory distress, need transfer to operation room and receive general anesthesia. Their short oral cavity limits in securing the RE instrument. The review suggests that these disadvantages can be effectively counteracted by the application of FE-NIV-SPI, especially in type I, II and III LC.

SPI with simultaneous chin-lift help to pneumatically expand the PLS including larynx, hypopharynx, esophageal inlet and upper esophagus. In our prior study ${ }^{19}$ of identical setting, the SPI with duration of 0 to 5 seconds could create linear correlated positive pressure levels from $4.1 \pm 3.3$ to $65.5 \pm 18.5 \mathrm{cmH}_{2} \mathrm{O}$ in PLS. When the nose was open (SPI 0 second), the intra-PLS pressure around $4.1 \pm 3.3 \mathrm{cmH}_{2} \mathrm{O}$, the surrounding structures were relatively collapse included the posterior glottis space. LC may be inadvertently overlooked as a result of redundant mucosa between esophagus and trachea apposing each other and sealing the cleft (Figure 2a), as those seven referred infants had done FE in the traditional way. During the SPI, the intra-PLS pressure gradually rising and sustaining up to $60 \mathrm{cmH}_{2} \mathrm{O}$, which were high enough to open the collapsed lumens of AET and the esophageal sphincter. These dynamic changes of pressure levels could be optionally and safely controlled by operator. The LC, if existed, could be well visualized (Figure 2b, c), probed and dispersed with the tip of FE or forceps to assess the depth and grading the cleft. The whole AET lumens, included trachea and esophagus, could be detail investigated. These dynamic events allowed for repeat and 
precise evaluation by FE.

This FE-NIV-SPI technique provides several advantages. 1) Oxygen insufflation alone through the nasopharyngeal catheter can flush upper airway dead space, as the effects of "apneic oxygenation", ${ }^{28-30}$ which can significantly prolong onset of desaturation. 2) Both assist inspiration and expiration can be achieved by simple maneuvers of nose-closure and abdomen-compression, respectively, to provide adequate oxygenation and PPV. 3) No other supplemental instruments such as mask, endotracheal tube, ventilation bag, or ventilator are needed, therefore it is cost-effective, eliminate procedural time and provide an unimpeded field for FE manipulation. 4) In addition to the LC, other coexisted lesions such as laryngomalacia, ${ }^{6}$ vallecular cyst, ${ }^{18,19}$ trachea, bronchial or esophageal pathologies also can be detected and managed in the same FE session. ${ }^{16,17}$ 5) Furthermore, it facilitates therapeutic interventions ${ }^{15-18}$ such as laser ablation, balloon measurement, stent implantation and repair in cardiopulmonary compromised children.

There are limitations in this study. 1) Although FE-NIV-SPI is easy for detecting most type I, II, and III LC, severe type IV LC may difficult to fully visualize and not with diagnostic certainty. Confirmatory RE is still necessary to determine the deeper cleft length and guide the management approach, as it remains the gold diagnostic standard. 2) Although the technique of FE-NIV-SPI have previously been reported, ${ }^{13-15}$ this may still be unfamiliar to many pediatric pulmonologists. Repetitive practice of this technique may be necessary to develop skill competency. 3) This report is from one single institution experience and the case number may not enough to make definitive conclusion. For this rare incidence and occult lesion of LC, further multi-center cooperative investigations are needed to verify the early detection with this FE-SPI technique.

\section{CONCLUSION}

Routine application of the FE-NIV-SPI technique for AET assessment could safely and rapidly detect the LC lesion at the first laryngeal inspection in infants. That may avert using other complicated diagnostic instruments.

\section{ACKNOWLEDGMENTS}

The study was supported by the Taipei Veterans General Hospital (2018-11-002BC) and the Medicine and Institute of Emergency and Critical Care Medicines, Medical School, National Yang-Ming Chiao-Tung University, Taiwan.

\section{Declaration of interest}

All authors declare that there is no any conflict of interests regarding the publication of this paper.

End.

\section{References}

1. Moungthong G, Holinger L. Laryngotracheoesophageal clefts. Ann Otol Rhinol Laryngol . 1997;106(12):1002-1011

2. Narcy P, Bobin S, Contencin P, et al. Laryngeal anomalies in newborn infants: apropos of687 cases. Ann Otolaryngol Chir Cervicofac . 1984;101(5):363-373 [in French].

3. Roth B, Rose KG, Benz-Bohm G, Gunther H. Laryngotracheoesophageal cleft: clinical features, diagnosis and therapy. Eur J Pediatr. 1983;140(1):41-46

4. Neubauer PD, Rosenthal LS, Drake AF, Zdanski CJ, Shah RN. Rigid Laryngoscopy Is Necessary to Diagnose Laryngeal Cleft. Otolaryngology - Head and Neck Surgery. 2011;145(2): P245 doi: 10.1177/0194599811415823a360 http://oto.sagepub.com/content/145/2_suppl/P245.2

5. Rahbar R, Rouillon I, Rogers G, et al. The presentation and management of laryngeal cleft: a 10-year experience. Arch Otolaryngol Head Neck Surg. 2006;132(12):1335-1341

6. Glossop LP, Smith RJ, Evans JN. Posterior laryngeal cleft: an analysis of ten cases. Int J Pediatr Otorhinolaryngol. 1984;7(2):133-143 
7. Chien W, Ashland J, Haver K, Hardy SC, Curren P, Hartnick CJ. Type 1 laryngeal cleft: establishing a functional diagnostic and management algorithm. Int J Pediatr Otorhinolaryngol. 2006;70(12):20732079

8. Langmore SE. Evaluation of oropharyngeal dysphagia: which diagnostic tool is superior? Curr Opin Otolaryngol Head Neck Surg.2003;11(6):485-489

9. Pezzettigotta SM, Leboulanger N, Roger G, et al. Laryngeal cleft.Otolaryngol Clin North Am. 2008;41(5):913-933

10. Eriksen C, Zwillenberg D, Robinson N. Diagnosis and management of cleft larynx: literature review and case report. Ann Otol Rhinol Laryngol. 1990;99(9 Pt 1 ):703-708

11. Parsons DS, Herr T. Delayed diagnosis of a laryngotracheoesophageal cleft. Int J Pediatr Otorhinolaryngol. 1997;39(2):169-173

12. Daniel Trachsel D, Hammer J. CPAP to diagnose laryngeal clefts by flexible endoscopy in infants. Pediatr Pulmonol 2018 Sep;53(9):1284-1287. doi: 10.1002/ppul.24117

13. Soong WJ, Jeng MJ, Lee YS, Tsao PC, Harloff M, Soong YH. A novel technique of non-invasive ventilation: pharyngeal oxygen with nose-closure and abdominal-compression-aid for pediatric flexible bronchoscopy. Pediatr Pulmonol. 2015;50:568-575.

14. Peng YY, Soong WJ, Lee YS, Tsao PC, Yang CF, Jeng MJ. Flexible bronchoscopy as a valuable diagnostic and therapeutic tool in pediatric intensive care patients: a report on 5 years of experience. Pediatr Pulmonol. 2011;46:1031-1037. https://doi.org/10.1002/ppul.21464

15. Soong WJ. Pediatric interventional flexible bronchoscopy. Pediatr Respiro Crit Care Med. 2018;2:3844.

16. Soong WJ, Tsao PC, Lee YS, Yang CF. Flexible endoscopy for pediatric tracheobronchial metallic stent placement, maintenance and long-term outcomes. PLoS One. 2018;13:e192557. https://doi.org/10.1371/journal.pone.0192557

17. Soong WJ, Tsao PC, Lee YS, Yang CF. Therapeutic flexible airway endoscopy of small children in a tertiary referral center-11 years' experience. PLoS One. 2017;12(8):e0183078. https://doi.org/10.1371/journal.pone.0183078

18. Soong WJ, Yang CF, Lee YS, Tso PJ, Lin CH, Chen CH. Vallecular cyst with coexisting laryngomalacia: successful diagnosis and laser therapy by flexible endoscopy with a novel noninvasive ventilation support in infants. Ped Pulmonol. 2020;55:1-7. https://doi.org/10.1002/ppul.24796

19. Soong W, Chen C, Lin C, Yang CF, Lee YS, Tsao PC, Sung YH, Dhochak N. Sustained pharyngeal inflation on upper airway effects in children-Flexible bronchoscopy measurement. Pediatric Pulmonology. 2021;1-8. https://doi.org/10.1002/ppul.25608

20. Benjamin B Inglis A. Minor congenital laryngeal clefts: diagnosis and classification. Ann Otol Rhinol Laryngol 1989; 6: 417-420.

21. Schnapf BM. Oxygen desaturation during fiberoptic bronchoscopy in pediatric patients. Chest1991;99(3):591-594

22. Prakash UB, Offord KP, Stubbs SE. Bronchoscopy in North America: the ACCP survey. Chest1991;100(6):1668-1675

23. Honeybourne D, Neumann CS. An audit of bronchoscopy practice in the United Kingdom: a survey of adherence to national guidelines. Thorax. 1997;52(8):709-713

24. Woodhull S, Goh EN, Lin TP, Chay OM. Pediatric flexible bronchoscopy in Singapore: a 10-year experience. J Broncho \& Intervent Pul. 2010;17(2):136-141

25. Lee YS, Soong WJ, Jeng MJ, Cheng CY, Shen CM, Sun J, Chen CF, Hwang B. Flexible endoscopy of aerodigestive tract in small infants. Pediatric Internat. 2003;45(5):530-533

26. Chen WT, Soong WJ, Chang HL, Lee YS, Jeng MJ, Hwang B. The safety of aerodigestive tract flexible endoscopy as an outpatient Procedure in young children. JCMA. 2008;71(3):128-134

27. Wood RE. Evaluation of the upper airway in children. Curr Opin Pediatr. 2008;20:266-271.

28. Soneru CN, Hurt HF, Petersen TR, Davis DD, Braude DA, Falcon RJ. Apneic nasal oxygenation and safe apnea time during pediatric intubations by learners. Paediatr Anaesth. 2019;29:628-634. https://doi.org/10.1111/pan.13645 
29. Riva T, Seiler S, Stucki F, Greif R, Theiler L. High-flow nasal cannula therapy and apnea time in laryngeal surgery. Paediatr Anaesth. 2016; 26:1206-1208.

30. Steiner JW, Sessler DI, Makarova N, et al. Use of deep laryngeal oxygen insufflation during laryngoscopy in children: a randomized clinical trial. Br J Anaesth. 2016;117:350-357.

\section{Legends}

Figure 1. Illustrations show flexible laryngoscopy with nasal pharyngeal oxygen. Laryngeal cleft cannot be detected during nose-open (a), but it become obvious gradually during sustained pharyngeal inflation by doing nose-closure (b).

Figure 2. Serial images of Laryngeal cleft (LC) with different durations of sustained pharyngeal inflation (SPI); nearly normal at SPI of 0 to 1 second (a) and the cleft gradually become obvious at 3 to 5 seconds $(\mathrm{b}, \mathrm{c})$.

End.
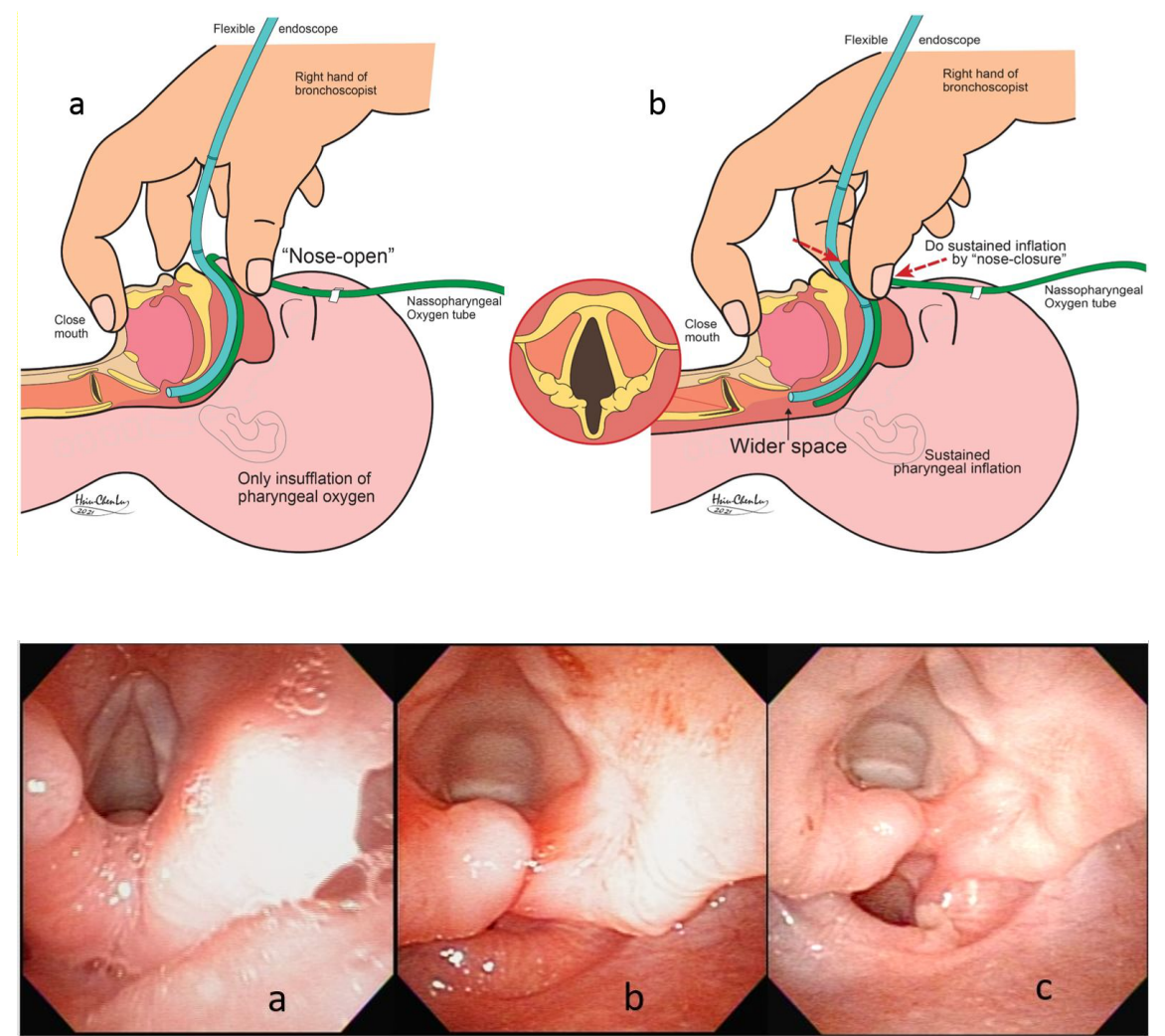

\section{Hosted file}

Table 1--202110.docx available at https://authorea.com/users/370890/articles/544071-earlydetection-of-laryngeal-cleft-in-infants-by-novel-technique-of-flexible-endoscopy-withsustained-pharyngeal-inflation 